\title{
Inventory Cost Minimization Through Item Categorization and Demand Forecasting: A Case Study-based Approach
}

\author{
M. H. Kibria, M. M. A. Khan*, A. B. M. A. Malek and P. K. Biswas \\ Department of Industrial and Production Engineering, \\ Shahjalal University of Science and Technology.
}

\begin{abstract}
Inventory of spare parts is needed for proper maintenance and repair of final products, vehicles, industrial machines and equipment. Holding of excess spare parts for long time generally results in extra cost (in form of holding cost, tied up capital and obsolescence cost). This study, therefore, tries to minimize the inventory cost through spare parts categorization and demand forecasting. $\mathrm{ABC}$ analysis was used to identify to most valuable items (Category A Items). Croston's method was used to determine forecasted demand of the Category A items obtained from $\mathrm{ABC}$ analysis. Existing spare parts inventory is found to hold a substantial fraction $(39 \%)$ of idle or unused items. Croston's method showed its potential in predicting the forecasted demand of Category $A$ items used in cement industries. Even though the ordering cost increases four times the existing one, the overall inventory cost of the Category A items decreases by $64 \%$ as compared to their existing inventory cost.
\end{abstract}

Keywords - Inventory Cost, Minimization, Item Categorization, Croston's Method

\section{INTRODUCTION}

Spare parts are interchangeable parts that are kept in an inventory and used for the repair or replacement of failed parts. Managing inventory of spare parts plays a vital role in many industries, such as aerospace and defense, transportation, telecommunications and information technology, utilities and durable goods suppliers, automotive, cement industries and manufacturing industries. Production plants hold spare parts for internal use in the maintenance of tools and equipment $[1,2]$.

Higher efficiency of production plants requires minimization of machine downtimes, and for reducing downtime, spare parts availability must be ensured. However, the availability of spare parts is limited by space and cost [3]. Hence, to overcome such a problem, spare parts inventory must be managed according to their criticality [4]. The criticality classification of spare parts is generally based on administrative efficiency considerations (such as inventory costs, usage rates, etc.) derived from historical data of the company [3]. Also, spare parts of the industrial maintenance are recommended to be classified according to such criticalities as vital, essential, and desirable (VED) [5]. Other facets of criticality such as response time, functionality, consumption, stage of the life cycle, price, purchase lead time, repairability, etc., are also used to evaluate the criticality of items [6].

Demands for spare parts are difficult to predict based on historical usages data because of their need only for maintenance either preventively or at failure [7]. Intermittent demand for spare parts is particularly challenging to predict, and shortage may result in extremely high costs [8]. Spare parts inventory management is, therefore, a very complex problem area for developing intelligent systems to assist in decision making [9]. Hence, it draws attention to many researchers to work on the spare parts inventory management issues. Antosz and Ratnayake applied the AHP technique to select items that need to be stocked on a priority basis [10]. Braglia and Montanari applied the AHP method together with Reliability Centered Maintenance (RCM) in order to develop an inventory management policy matrix for different spare parts [3]. Eaves and Kingsman tried to find out a forecasting method best-suited for a spare part inventory with smooth, irregular, slow-moving, and intermittent demand patterns [11]. Ramanathan developed a weighted linear optimization method to solve the multicriteria ABC inventory classification problem, which intuitively assigns weights to each criterion [12]. Li and Kuo developed an Enhanced Fuzzy Neural Network (EFNN) based decision support system to forecast the demand for automobile spare parts and hence, to manage the inventory in a central warehouse [13]. Gutierrez et al. developed a Neural Network based model in forecasting lumpy demand [14]. Their model's performance was found to be superior to the exponential smoothing, SBA, and Croston's method.

From the above literature, it is evident that managing spare parts is a complicated problem but a critical issue for the inventory cost reduction and the efficiency enhancement of production equipment as well. Depending on the types and demand patterns of the spare parts, different techniques have been found competent for managing the inventory of spare parts of different sorts. Though different Neural Network-based techniques showed enormous potential in forecasting the demand of the spare parts, no one tries to use these techniques to minimize the inventory management cost so far. This study, therefore, tries to minimize the inventory cost through spare parts categorization and demand forecasting. This study focuses on:

- Categorizing the spare parts used in the cement industries into moving and nonmoving groups and then, estimating the most valuable moving spare parts (Category-A Items) performing ABC analysis;

- $\quad$ Selecting a forecasting method able to predict the demand of the Category- A items most accurately; and

- Finally, applying the spare part categorization and the selected demand forecasting techniques to minimize the overall inventory cost of the Category-A items. 


\section{METHODOLOGY}

\section{A. Data collection}

The data on spare parts issued or received daily was collected from a rich administrative database available in a multinational cement company located in Sylhet, Bangladesh, using a predesigned table. The table contained such information as item codes, item descriptions, ordered date, transaction explanation (received or issued), transaction quantities, unit measurement, and unit cost/price. Data were limited to 2007 through 2018. Within the stated period, the number of records for items issued was found to be 106905,49162 for items received, and 7572 records of current inventory. The total number of items in different categories was 11952.

\section{B. Item Categorization}

In this study, items were categorized as moving and nonmoving. Items not used for more than three years were termed as non-moving inventory. Items used at least once a year were designated as slow-moving inventory, and very high consumption and frequently moving items were denoted as fast-moving. However, in this study, slow-moving items were considered as moving items. Stockout items, critical items, and unused (idle) items were categorized as non-moving items. This is worth mentioning that idle items incur three types of cost, which, in turn, increase the loss for the company, e.g., Total purchase cost $=$ No of total quantity $\mathrm{x}$ unit cost; Total holding cost $=$ No of year $\mathrm{x}$ holding cost Cost of capital $=$ Total cost year $\mathrm{x}$ percentage of interest; and Total loss $=$ Total cost + Holding cost + Cost of capital.

Moreover, in this study, to optimize the cost of moving items, $\mathrm{ABC}$ analysis was used to identify to most valuable items (Category A Items), and then the EOQ model was applied to determine the optimum order size of category A items. In the $\mathrm{ABC}$ analysis, for the studied company, the classification rule shown in Table 1 was implemented:

Table 1: Classification rule applied in this study

\begin{tabular}{|c|c|c|}
\hline Classification & $\begin{array}{c}\text { Percentage of total } \\
\text { number of items }\end{array}$ & $\begin{array}{c}\text { Percentage of the total } \\
\text { cost }\end{array}$ \\
\hline A & $5-20 \%$ & $50-80 \%$ \\
\hline B & $20-40 \%$ & $20-40 \%$ \\
\hline C & $50-70 \%$ & $5-25 \%$ \\
\hline
\end{tabular}

\section{Demand Forecasting of category-A items}

Forecasting serves as a decision support tool that allows us to determine how changes in inputs affect outcomes. The forecast period determines the priorities of forecast method application, which is traditionally divided into short (1-3 months), mid (3 months-2 years), and long (more than two years). Simple quantitative forecast methods are applied for a short and mid-period (simple moving average and potential smoothing), while for a long-term forecast, regression and econometric models are applied. However, the spare part items demand is typically intermittent (highly variable and arrive sporadically). For intermittent demand, Croston's proposes a method, which is similar to traditional exponential smoothing (ES) when demand is steady [11].

According to Croston's method, forecasted of demand per period is calculated by dividing mean demand size by mean demand interval, that is:

$\mathrm{F}_{\mathrm{t}+1}=\frac{\mathrm{Z}_{\mathrm{t}+1}}{\mathrm{P}_{\mathrm{t}+1}}$

Here, $F_{t+1}=$ forecast mean demand for period $t+1$

$\mathrm{Z}_{\mathrm{t}+1}=$ forecast demand size for period $\mathrm{t}+1$

And $P_{t+1}=$ forecast interval between transaction for period $t+1$ If the actual demand at time $t$ is $D_{t}$ is zero then,

$\mathrm{Z}_{\mathrm{t}+1}=\mathrm{Z}_{\mathrm{t}}$

$\mathrm{P}_{\mathrm{t}+1}=\mathrm{P}_{\mathrm{t}}$

But, if the actual demand at time $t$ is more than zero, then

$\mathrm{Z}_{\mathrm{t}+1}=\alpha \mathrm{D}_{\mathrm{t}}+(1-\alpha) \mathrm{Z}_{\mathrm{t}}$

$\mathrm{P}_{\mathrm{t}+1}=\alpha \mathrm{Q}_{\mathrm{t}}+(1-\alpha) \mathrm{P}_{\mathrm{t}}$

Here, $Q_{t}=$ actual value of the time between consecutive transactions at the instant $\mathrm{t}$; if demand at $\mathrm{t}-1$ is greater than zero then $\mathrm{Q}_{\mathrm{t}}=1$, and if demand at $\mathrm{t}-1$ is zero than $\mathrm{Q}_{\mathrm{t}}=\mathrm{Q}_{\mathrm{t}-1}+1 \alpha=$ smoothing constant.

Syntetos-Boylan Approximation (SBA) method is a modification to the Croston's method. Syntetos and Boylan suggested a deflating factor to the estimate of mean demand per period based on the smoothing parameter for demand interval $\alpha$. Hence, the modified model describing the forecasted demand per period becomes:

$\mathrm{F}_{\mathrm{t}+1}=\left(1-\frac{\alpha}{2}\right) \frac{\mathrm{Z}_{\mathrm{t}+1}}{\mathrm{P}_{\mathrm{t}+1}}$

\section{Forecasting Error Estimations}

The forecasting error (forecast value - actual value) is frequently estimated to identify the most accurate forecast method. For this purpose, many estimators like MAD (Mean Absolute Deviation), MSE (Mean Squared Error), or RMSE (Root Mean Squared Error), MAPE (Mean Absolute Percentage Error) are usually used.

MAD is considered as a standard method due to its simplicity. MAD is calculated as:

$\mathrm{MAD}=\frac{\sum\left|F_{t}-D_{t}\right|}{N}$

Here, $F_{t}=$ forecasted value; $D_{t}=$ actual value and $\mathrm{N}=$ number of year.

RMSE (Root Mean Squared Error) is calculated as:

$\operatorname{RMSE}=\sqrt{\frac{\sum\left(F_{t}-D_{t}\right)^{2}}{N}}$

Here, $\mathrm{F}_{\mathrm{t}}=$ forecasted value; $\mathrm{D}_{\mathrm{t}}=$ actual value and $\mathrm{N}=$ number of year.

For intermittent demand, MAPE (Mean Absolute Percentage Error) has some drawbacks because some actual value of demand became zero. Hence Symmetric Mean Absolute Percentage Error (SMAPE) is used instead and calculated as:

SMAPE $=\frac{1}{\mathrm{~N}} \sum_{\mathrm{t}=1}^{\mathrm{N}} \frac{\left|F_{t}-D_{t}\right|}{\left|F_{t}+D_{t}\right|}$

Here, $\mathrm{F}_{\mathrm{t}}=$ forecasted value; $\mathrm{D}_{\mathrm{t}}=$ actual value and $\mathrm{N}=$ number of year. 


\section{E. Total Inventory Cost}

The total inventory cost function, includes economic order quantity, Q, the size of the safety stock, s, order frequency, $\mathrm{D} / \mathrm{Q}$ and the purchase price, $\mathrm{PD}$ of the item being ordered, i.e.,

$C_{t}=C_{h}\left(\frac{Q}{2}+s\right)+\frac{C_{o} D}{Q}+P D$

Where $\mathrm{C}_{\mathrm{h}}$ is total holding costs, $\mathrm{C}_{\mathrm{o}}$ is ordering costs, $\mathrm{P}$ is the unit price of the item purchased, and $\mathrm{D}$ is the annual demand of that particular item.

$F$. The economic order quantity for A-category items In this study, the basic model given below is used to determine the optimal order quantity minimizing the sum of carrying costs and ordering costs.

$Q=E O Q=\sqrt{\frac{2 C_{o} D}{C_{h}}}$

G. $(S, s)$ policy model with specific service level for Acategory items

For the basic EOQ model, no safety stock is necessary as this model assumes the demand and the lead time constant. However, for the items considered in this study, demand for the spare parts is stochastic and hence, assumed to be normally distributed, whereas replenishment lead times are assumed fixed and known.

Thus, the $(\mathrm{S}, \mathrm{s})$ policy model with a specific service level is used to determine the size of the safety stock. Also, the reorder point is set to cover the expected demand during the lead time, as well as a safety stock determined by the desired service level.

For a lead-time demand that follows a normal distribution with a mean of $L D$ and standard deviation of $\sigma \sqrt{L}$, the safety stock can be calculated as:

$\mathrm{s}=\mathrm{Z} \times$ standard deviation of lead-time demand $=Z \sigma \sqrt{L}$

Where, $\mathrm{Z}$ is the number of standard deviations for a specific service level, and $\mathrm{L}$ denotes the lead time.

\section{RESULTS AND DISCUSSION}

\section{A. Spare Parts Categorization}

In this study, spare parts are initially classified as moving and non-moving items. As mentioned earlier, any spare part, which was used at least once in a designated period, was identified as a moving item. Whereas, spare parts with no use within that designated period were identified as non-moving items. Fig. 1 illustrates the distribution of moving and nonmoving items found in the existing inventory. From the figure, it is found that the existing inventory contains more nonmoving spare parts $(54 \%)$ than the moving ones. This fact indicates that the current inventory is holding more items unnecessarily, incurring more holding costs and hence, contributing more to the total inventory cost.

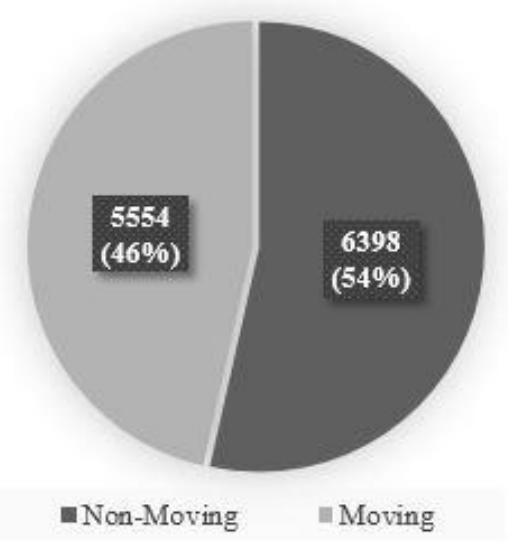

Figure 1: Moving and non-moving items category in total items

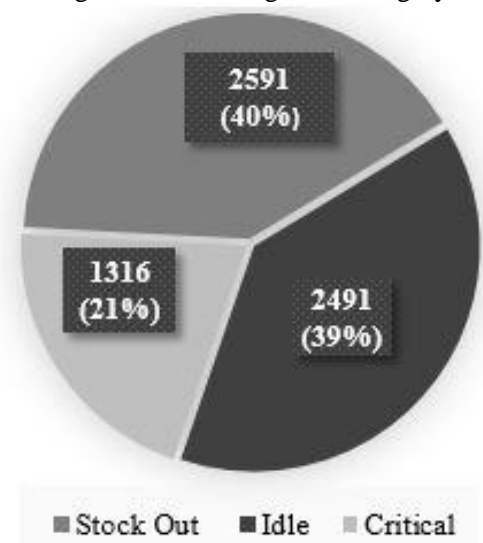

Figure 2: Category of Non-moving items

The non-moving items are further classified as critical, stock out, and idle. In this study, a non-moving spare part having a longer lead time, incurring a higher cost, and essential for proper functioning is termed as a critical item. Items used earlier but not found in the current inventory are labeled as stock-out items. Any non-moving item apart from the critical and stock-out items is called as idle or unused items, which only contribute to the cost increment. Fig. 2 shows the distribution of critical, stock out, and idle or unused non-moving items. From the figure, it is apparent that among non-moving items, $40 \%$ are stock-out items, $39 \%$ are idle, and the rest $21 \%$ are critical items that must be kept in the inventory and, thus, should be incorporated in inventory cost estimation. However, the aforestated data indicate the fact that there is an ample opportunity for eliminating unused items from the existing inventory and hence, for reducing the inventory costs.

\section{B. Estimating Most Valuable Moving Spare Parts}

In this study, $\mathrm{ABC}$ analysis is performed to identify the items contributing the most to the overall inventory cost. Fig 3 depicts the variation in overall inventory cost with the number of items. From the figure, it is apparent that 552 items (category A) incur $81.8 \%$ of the overall inventory cost, which is only $10 \%$ of the total moving items. Whereas $70 \%$ of the items (category C) incurs less than $5 \%$, which is insignificant as compared to Category A items. For this reason, in this study, only the category A items are considered while minimizing the overall inventory cost. 


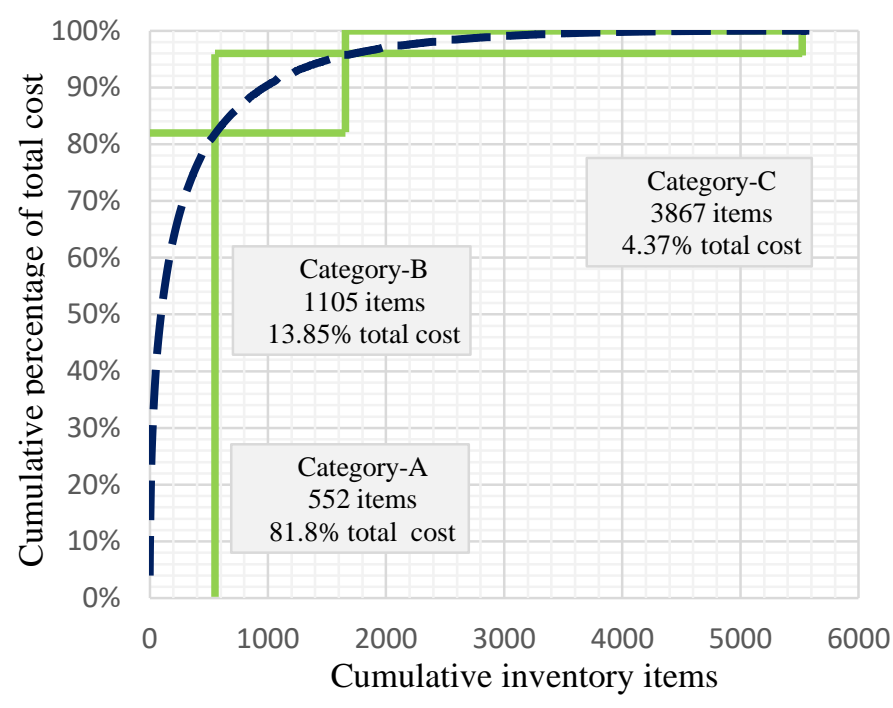

Figure 3: $\mathrm{ABC}$ analysis on moving items

\section{Selecting the Demand Forecasting Technique for Category} A Spare Parts

In this study, different methods are first used to calculate the forecasted demand of the Category $\mathrm{A}$ items, and then the forecasting errors associated with each method are estimated and compared to determine the method most suitable for forecasting the demand of these items. The forecasting methods chosen here are three years, five years and seven years moving average; exponential smoothing with a constant of $0.3,0.5$ and 0.8 ; Croston's method; and Syntetos-Boylan Approximation. In this case, a single item from category A is randomly sampled, and forecasting errors like MAD (Mean Absolute Deviation), RMSE (Root Mean Squared Error), SMAPE (Symmetric Mean Absolute Percentage Error) values are estimated for each technique.

Table 2 presents the MAD, RMSE, and SMAPE values estimated for different forecasting techniques for a random item. As shown in the table, MAD, RMSE, and SMPE values estimated for Croston's method are relatively small as compared to the other. These results indicate that Croston's method is highly effective as compared to others and can be used to determine the forecasted demand for the category A spare part.

\section{Inventory Cost Reduction through Parts Categorization and Demand Forecasting}

As stated earlier, the overall inventory cost is a function economic order quantity $\mathrm{Q}$, the size of the safety stock s, order frequency $\mathrm{D} / \mathrm{Q}$, and the purchase cost $\mathrm{PD}$ of the item being ordered. In this study, Croston's method is used to find the annual forecasted demand D; the basic EOQ model is applied to determine the economic order quantity $\mathrm{Q} ;(\mathrm{S}, \mathrm{s})$ policy model with a $95 \%$ service level and a fixed lead time of 20 days is used to calculate the safety stock.

Table 3 shows how the demand forecasting affects the different inventory cost categories associated with Category A items. From the table, it is evident that applying Croston's technique for forecasting the demand causes a reduction in holding cost and item cost by $96 \%$ and 59\%, respectively. Even though the current ordering cost increases almost five times the previous ordering cost incurred, the overall inventory cost of Category A items decreases by $64 \%$.

Table 3: Effect of demand forecasting on inventory cost distribution for category A items

\begin{tabular}{|l|c|c|c|c|}
\hline & $\begin{array}{c}\text { Holding } \\
\text { Cost }\end{array}$ & $\begin{array}{c}\text { Ordering } \\
\text { cost }\end{array}$ & $\begin{array}{c}\text { Items } \\
\text { cost }\end{array}$ & $\begin{array}{c}\text { Inventory } \\
\text { Cost }\end{array}$ \\
\hline $\begin{array}{l}\text { Before Demand } \\
\text { Forecasting }\end{array}$ & 106.8 & 0.5 & 646.5 & 753.9 \\
\hline $\begin{array}{l}\text { After Demand } \\
\text { Forecasting }\end{array}$ & 4.2 & 2.9 & 262.8 & 269.9 \\
\hline $\begin{array}{l}\text { Fraction } \\
\text { (Increase)/Decr } \\
\text { ease in Each } \\
\text { Cost Item }\end{array}$ & 0.96 & $(4.80)$ & 0.59 & 0.64 \\
\hline
\end{tabular}

Table 4: Inventory cost distribution for non-moving items

\begin{tabular}{|c|c|c|}
\hline \multirow{2}{*}{ Cost Items } & \multicolumn{2}{|c|}{ Non-moving Items } \\
\cline { 2 - 3 } & Critical items & Idle items \\
\hline Total Purchase Cost & 140.3 & 188.1 \\
\hline Holding cost & 6.8 & 11.5 \\
\hline Opportunity Cost & 102.2 & 124.4 \\
\hline Total Cost & 249.3 & 324.0 \\
\hline
\end{tabular}

Moreover, from figure 1 and 2, it is apparent that non-moving parts outnumbered moving ones, and the idle or unused parts, in particular, covered almost two-fifth of the non-moving parts. Hence, the overall inventory cost can further be reduced by eliminating the unused items from the existing inventory, as can be seen from Table 4 .

Table 2: Estimation of MAD, RMSE \& SMAPE for different forecasting method

\begin{tabular}{|l|c|c|c|c|c|c|c|c|}
\hline $\begin{array}{l}\text { Type of } \\
\text { error }\end{array}$ & $\begin{array}{c}\text { Simple } \\
\text { moving } \\
\text { average } \\
(\mathrm{k}=3)\end{array}$ & $\begin{array}{c}\text { Simple } \\
\text { moving } \\
\text { average } \\
(\mathrm{k}=5)\end{array}$ & $\begin{array}{c}\text { Simple } \\
\text { moving } \\
\text { average } \\
(\mathrm{k}=7)\end{array}$ & $\begin{array}{c}\text { Exponential } \\
\text { smoothing } \\
\text { for } 0.3\end{array}$ & $\begin{array}{c}\text { Exponential } \\
\text { smoothing } \\
\text { for 0.5 }\end{array}$ & $\begin{array}{c}\text { Exponential } \\
\text { smoothing } \\
\text { for 0.8 }\end{array}$ & $\begin{array}{c}\text { Croston's } \\
\text { Method }\end{array}$ & SBA \\
\hline $\begin{array}{l}\text { Error } \\
\text { Difference }\end{array}$ & 753 & 572.00 & 531.71 & 674.03 & 691.34 & 705.74 & 500.46 & 542.4 \\
\hline MAD & 83.67 & 81.71 & 106.34 & 67.40 & 69.13 & 70.57 & 45.50 & 49.31 \\
\hline RMSE & 99.67 & 99.90 & 115.83 & 89.00 & 86.27 & 85.72 & 64.16 & 67.66 \\
\hline SMAPE & $68 \%$ & $64 \%$ & $64 \%$ & $59 \%$ & $60 \%$ & $60 \%$ & $40 \%$ & $43 \%$ \\
\hline
\end{tabular}




\section{CONCLUSIONS}

This study aims at reducing the inventory cost of the spare parts used in the cement industries through parts categorization and demand forecasting techniques. Conclusions can be summarized as follows:

- Existing spare parts inventory is unnecessarily holding a substantial fraction of idle or unused items, and hence, only contributing to the inventory cost of the spare parts;

- As compared to exponential smoothing with different constants and Syntetos-Boylan Approximation, Croston's method found to be more accurate in forecasting, and can be used in predicting the forecasted demand of Category A items used in cement industries; and

- Though the application of forecasting technique in spare parts inventory management significantly increases the ordering cost, the overall inventory cost of the Category A items becomes less by two-third of their existing inventory cost.

\section{REFERENCES}

[1] Lengu, D., Syntetos, A. A., \& Babai, M. Z. (2014). Spare parts management: Linking distributional assumptions to demand classification. European Journal of Operational Research, 235(3), 624635.

[2] Diaz, D. A. B., Hennequin, S., \& Roy, D. (2019, July). Spare Parts Management in the Automotive Industry Considering Sustainability. In World Congress on Global Optimization (pp. 1109-1118). Springer, Cham

[3] Braglia, M., Grassi, A., \& Montanari, R. (2004). Multi-attribute classification method for spare parts inventory management. Journal of quality in maintenance engineering, 10(1), 55-65.
[4] Sharaf, M. A., \& Helmy, H. A. (2001, February). A classification model for inventory management of spare parts. In INTERNATIONAL CONFERENCE ON PRODUCTION, INDUSTRIAL ENGINEERING, DESIGN AND CONTROLPEDAC (Vol. 7, p. 2001)

[5] Gajpal, P. P., Ganesh, L. S., \& Rajendran, C. (1994). Criticality analysis of spare parts using the analytic hierarchy process. International journal of production economics, 35(1-3), 293-297.

[6] Botter, R., \& Fortuin, L. (2000). Stocking strategy for service parts-a case study. International Journal of Operations \& Production Management, 20(6), 656-674.

[7] Wang, W. (2012). A stochastic model for joint spare parts inventory and planned maintenance optimisation. European Journal of Operational Research, 216(1), 127-139.

[8] Hua, Z. S., Zhang, B., Yang, J., \& Tan, D. S. (2007). A new approach of forecasting intermittent demand for spare parts inventories in the proces industries. Journal of the Operational Research Society, 58(1), 52-61.

[9] Boylan, J. E., Syntetos, A. A., \& Karakostas, G. C. (2008). Classification for forecasting and stock control: a case study. Journal of the operational research society, 59(4), 473-481.

[10] Antosz, K., \& Ratnayake, R. C. (2019). Spare parts' criticality assessment and prioritization for enhancing manufacturing systems' availability and reliability. Journal of Manufacturing Systems, 50, 212 225.

[11] Eaves, A. H., \& Kingsman, B. G. (2004). Forecasting for the ordering and stock-holding of spare parts. Journal of the Operational Research Society, 55(4), 431-437.

[12] Ramanathan, R. (2006). ABC inventory classification with multiplecriteria using weighted linear optimization. Computers \& Operations Research, 33(3), 695-700.

[13] Li, S. G., \& Kuo, X. (2008). The inventory management system for automobile spare parts in a central warehouse. Expert Systems with Applications, 34(2), 1144-1153.

[14] Gutierrez, R. S., Solis, A. O., \& Mukhopadhyay, S. (2008). Lumpy demand forecasting using neural networks. International Journal of Production Economics, 111(2), 409-420. 